Int. J. Electrochem. Sci., 12 (2017) $8599-8608$

\title{
Electrochemical Study of the Herbicide Paraquat Based on a Graphene-Zinc Oxide Nanocomposite
}

\author{
Hua Liu', Maoqi Chen ${ }^{1}$, Yi Lin ${ }^{1}$ and Yanhong Liu ${ }^{2, *}$ \\ ${ }^{1}$ Department of Biomedical Engineering, Guangdong Pharmaceutical University, Guangzhou 510006, \\ China \\ ${ }^{2}$ Department of Endocrinology, The Second People's Hospital of Hengshui, Hengshui 053000, China \\ "E-mail: hswyliuyanhong@sina.com
}

doi: $10.20964 / 2017.09 .15$

Received: 24 May 2017 / Accepted: 22 June 2017 / Published: 13 August 2017

\begin{abstract}
Detection of the herbicide paraquat (PQ) is of great significance in the field of agriculture. To detect $\mathrm{PQ}$, this work proposed the fabrication of a new electrochemical sensor based on graphene oxide/ $\mathrm{ZnO}$ nanorod $(\mathrm{GR} / \mathrm{ZnO})$-modified graphite screen-printed electrodes (SPEs). SPEs were used since they are small, low-cost and versatile. The GR/ZnO-modified SPE was prepared by casting a nanocomposite of the GR/ZnO nanorods on the SPE surface. The two reduction DPV peaks of PQ were remarkably strengthened with $\mathrm{GR} / \mathrm{ZnO}$ at $-0.60 \mathrm{~V}$ and $-1.00 \mathrm{~V}$. The reduction peak currents of $\mathrm{PQ}$ on the GR/ZnO-modified SPE were linear under the optimal conditions (concentration range: 0.05-2 $\mu \mathrm{M}$ ), and the limit of detection (LOD) was $21 \mathrm{nM}$.
\end{abstract}

Keywords: Graphene oxide/ZnO nanorods; Screen-printed electrodes; Graphene; Electrochemical determination; Paraquat

\section{FULL TEXT}

(C) 2017 The Authors. Published by ESG (www.electrochemsci.org). This article is an open access article distributed under the terms and conditions of the Creative Commons Attribution license (http://creativecommons.org/licenses/by/4.0/). 